\title{
humanidades
}

Revista humanidades

Enero-junio, 2016 • Volumen 6, número 1・ISSN 2215-3934・pp. 1-28

\section{Sensibilidad y políticas de la sensación}

DOI: http://dx.doi.org/10.15517/h.v6i1.24960

\section{Benjamín Valdivia}

Doctor en Filosofía y en Artes y Humanidades. Coordinador del programa académico de Doctorado y Maestría en Artes de la Universidad de Guanajuato, Campus Guanajuato.

Correo electrónico: benjamin@valdivia.mx

Todos los derechos reservados. Universidad de Costa Rica. Esta revista se encuentra licenciada con Creative Commons Reconocimiento-NoComercial-SinObraDerivada 3.0 Costa Rica.

Correo electrónico: humanidades@ucr.ac.cr / Sitio web: http://revistas.ucr.ac.cr/index.php/humanidades 


\title{
Sensibilidad y políticas de la sensación
}

\section{Resumen}

Las sociedades tienden a mantener identidades basadas en la comunidad de significados culturales, premiando la pertenencia y disuadiendo la divergencia. Para asegurar esas permanencias simbólicas se establecen las políticas culturales, vinculadas fuertemente con la permisión y la prohibición del ejercicio de la sensorialidad, a fin de fortalecer la subsistencia de la tradición. Pero también la sociedad requiere renovaciones de la sensibilidad, lo cual crea contradicciones en las políticas de la sensación, las cuales se plantean y discuten en el presente texto.

\section{Sensitivity and Politics for Sensation}

\begin{abstract}
The aim of this paper is to present and discuss the politics of sensation related to sensitivity and its exercise by communities. Politics of sensation imply contradictions inside society, since they represent the most traditional and the newest forms of sensitivity expressed by acts and symbols with a cultural significance. Society rewards integration and disregard divergence, by means of permission or prohibition of sensations inside its groups, in order to make tradition stronger, but looking at emerging of the new.
\end{abstract}

Palabras clave:

Sensibilidad, políticas, sensación, identidad, cultura.

Keywords: Sensitivity, politics, sensation, identity, culture. 
La percepción y la sensación son formas imprescindibles de la sensibilidad, sobre todo en el campo del arte, donde siempre se crea algo para los sentidos. La percepción es el inicio en la transformación de lo imaginario. En cada momento específico de la historia, la similitud de percepciones permite apreciar al conjunto de la sociedad como una unidad cultural. Existe, claro está, una relación directa entre dicha unidad cultural y las transformaciones en el campo del arte. El conjunto social, por medio de sus poderes constituidos, ejerce lo que se plantea en este artículo como políticas de la sensación ${ }^{1}$, las cuales son parte integral de la política cultural.

Aunque las políticas culturales siempre se han ejercido como toma de decisiones acerca de lo prohibido y lo permitido ante los bienes que conforman e identifican al grupo social, en tanto conciencia del poder, son cosa del siglo veinte. Como en todas las políticas, su ejercicio pertenece a quien detenta el poder. En ese caso, se debe caracterizar la política cultural como algo que el Estado ejerce mediante sus criterios para decidir entre lo permitido y lo prohibido en la cultura ${ }^{2}$. Se observan por separado el Estado, la política y la cultura, los tres elementos que participan en esta circunstancia.

Al Estado hay que considerarlo, en su orden más concreto, como el conjunto de los poderes de una nación; claro que se puede entender también como el sustentador de los aparatos ideológicos ${ }^{3}$. Pero dichos aparatos son para sistematizar la garantía de la nación, en tanto implican gente y territorios: eso es lo que el Estado puede controlar y defender con su poder. En el caso de un Estado que no puede defender o controlar a su población y territorio, el poder se ve disminuido o, incluso, anulado. Por ejemplo, el 
Estado mexicano, a mediados del siglo XIX, sustentó a una nación que se logró uniendo diferentes culturas: mayas, aztecas, purépechas, españoles y todos los demás grupos; es decir, se constituyó en un poder ejercido en un territorio sobre una población determinada. Cuando el presidente Antonio López de Santa Anna acuerda con Estados Unidos la mutilación de más de la mitad del territorio mexicano, reduce drásticamente el poder del Estado nacional y segrega la población. El poder del Estado mexicano se redujo hasta donde alcanzó a defender el territorio y la población, disminuyendo así el sentido histórico de la nación mexicana y, en consecuencia, aumentando el poder de los Estados Unidos.

El Estado, como suma de los poderes de una nación, tendría a su alcance los recursos para mantener sus fronteras territoriales y que la población tenga la libertad de vivir dentro de ese territorio. Unos Estados tienen más fuerza que otros, con la consecuente guerra por predominar y controlar, tal como la han ejercido los imperios en todo tiempo y hasta nuestros días; sin embargo, dentro del propio territorio, y por intereses de la propia población, cada Estado se encuentra en disputa, por lo que, el grupo poblacional que administra no tiene el control absoluto, ni del territorio ni de la población.

Hay acontecimientos dentro de la sociedad que el Estado no controla; pero si se aplica la definición abstracta, este derecho o este acto de oponerse al Estado como estructura, también es parte del Estado. Dicho de otra forma, el Estado mantiene su unidad incluyendo a sus oposiciones. Pareciera no ser así en el caso de alguien que utiliza la violencia terrorista, o incluso cuando comete un delito grave que lo sitúe como enemigo del Estado. No obstante, se aprecia con toda claridad en los congresos nacionales, donde actúan diputados que están abiertamente en contra del Estado o de su forma 
de organización. Son oposición al grupo dominante, pero devengan salarios y ejercen por sí mismos el poder del Estado, en lo que corresponde al congreso respectivo. El conjunto de poderes dentro de la sociedad no incluye solo a los dominantes, sino también a los que se pueden llamar beligerantes, incluso, aislados emergentes.

Se distinguen, entonces, tres tipos de poderes: el dominante, el beligerante y el emergente. El Estado incluye proporciones de los tres: un poder que domina y administra los controles; uno que se le opone de forma beligerante, con aspiraciones de obtener la administración de los controles sociales; y otro emergente, que surge sin llegar a ser beligerante. Este último no hace mella a la dominación. En términos teóricos, el Estado es la suma de los poderes de una nación. Es claro que, si bien el poder dominante rige en la mayor parte, junto a él hay un poder beligerante que controla un territorio y una población dentro de la misma nación, por lo cual, constituye parte del Estado, de aquello que la nación tiene para defensa de su territorio y de su población.

El Estado es el poder que suma de todo lo que la sociedad tiene para su sobrevivencia en cierto momento. Cuando la sociedad no cuenta con poder para su defensa, la nación pierde territorio, pierde población y, desde luego, pierde poder cuando el Estado queda fragmentado. El Estado, en general, es la suma de poderes que son dominantes, beligerantes o emergentes; pero, en lo particular, es visto como un conjunto de instituciones, como un control organizado y administrado, ya no como un poder en términos teóricos. Así, debe ser visto como una estructura institucional. En su acomodo específico es donde los poderes se constituyen institucionalmente. Dejan de ser nociones abstractas y devienen como un conjunto organizado de estructura, presupuesto y legislación: política, 
economía y derecho. Estos tres elementos se reúnen para conformar la institucionalidad.

Las políticas, la legislación y los presupuestos se comportan de modo sistemático para defenderse unas a otras y garantizar, en todo lo posible, que el poder dominante siga siéndolo. Así, el Estado es autoinmune. En términos ideológicos, el poder dominante busca que la sociedad acepte una identidad del Estado —o incluso de la nación — con ese poder dominante, excluyendo otras formas sociales del poder. El dominador busca reducir el Estado a su propio poder: se mencionó que el Estado es lo que alcanza nuestro poder. Si alguien se opone al poder dominante, se dice que se opone al Estado que está en contra del Estado. Ese enfoque es ya una posición política, expresada en términos ideológicos; y, desde luego, no abarca toda la realidad, ni teórica ni práctica, de lo que es el poder.

Por ejemplo, existe el gobernador de un Estado; él administra, pero supone un auténtico poder dominante que lo impuso para gobernar. En el ideal democrático, ese poder reside en el pueblo que lo eligió. En la vida real, el pueblo se agrupa en diferentes tendencias políticas que no se sienten representadas. El segundo ideal democrático es que no es el pueblo, sino la mayoría, quien delega el poder en el gobernador. Pero esa mayoría, cambiante siempre, se siente defraudada por el gobernante, cuyos intereses no coinciden con los de la mayoría que lo eligió. Existe un desfase entre los grupos de poder, los individuos que administran el Estado y las mayorías participativas.

El poder dominante se apropia de la legislación, la economía y la política. Así, la política no se debe confundir con el Estado; y mucho menos con el poder. La política solo es el modo de organizar la polis, la convivencia de los ciudadanos, y no es equivalente ni al gobierno ni al poder. Entonces 
comienzan a adelantarse unos a otros los conceptos. El análisis político debe hacer notar, en cada situación, quién gana dinero o quién gana poder. En última instancia, el dinero y el poder van juntos; quien tiene uno o los dos elementos es el que tiene el poder real para imponer su ley.

Las formas de proceder en la polis se constituyen por los tres elementos señalados, por lo cual el Estado, en lo particular, sería el conjunto de instituciones que la ley determina con montos para su financiamiento y reglas para su operación.

Ante los grupos sociales, los poderes se ejercen, por la orientación que tienen, las instituciones. En el ejercicio de la acción institucional, los grupos sociales se convierten en grupos de interés que tienden a mantenerse y repetirse. Queda claro, pues, que el poder, con todo su contenido abstracto y genérico, es un accionar humano: las instituciones y el Estado se componen de personas. En ese sentido, no existe un poder abstracto. En su novela El proceso, Kafka muestra una entidad trascendental insuperable que agobia y controla a todos los individuos para que ocupe cada cual su sitio debajo del poder. Lo ominoso en dicha novela es, precisamente, el ejercicio de un poder abstracto, más allá de cualquier individuo.

Desde luego que ese poder es sistemático y está organizado para someter a cada individuo en lo particular, por eso se le conoce como "el sistema". Pero en cada instante se ejecuta ese poder, debido a la acción de un individuo: el policía pudo no haber arrestado al protagonista; o el fiscal no acusarlo; o el juez no condenarlo; o el verdugo no ejecutarlo. Es decir, la inminencia del poder se concreta siempre en la acción de un individuo que reproduce el orden del sistema: el poder se ejerce por personas en 
particular. Quien da la orden no es “el poder" en abstracto, sino una persona o un grupo de personas en asociación. Estos conceptos abstractos se muestran como ejercicios del poder por personas en particular o por grupos muy específicos.

El poder dominante se concreta en la voluntad e imposición de quienes pueden decidir a favor o en contra de lo que ellos quieran, a pesar de la oposición de otras personas o grupos, con los que el dominante convive o a los que elimina. El Estado es la suma de todos los poderes; y uno de estos poderes es dominante, ejercido por seres humanos en lo particular, con sus propios nombres, biografías y asociados que forman una fracción del total social. Cuando esa fracción dominante decide, lo hace por todos. A eso se 1lama democracia. ${ }^{4}$

El Estado, entonces, se constituye por voluntades particulares y ejercicios particulares del poder. Esto es importante, porque las políticas incluyendo las culturales - no las activa el Estado o el poder, como entidades abstractas, sino una persona que rige una institución o dependencia y toma esas decisiones, incluso en contra de la mayoría de la sociedad, debido a que es parte del grupo que detenta el poder dominante. Un corolario general es que toda dominación del Estado es el ejercicio de una dominación humana sobre otros humanos. Vale señalar que, si bien el ejercicio del poder es una dominación, no todo poder se ejerce en contra del beneficio de la sociedad.

La política es el ejercicio particular del poder dentro del Estado, que implica controles, emergencias y beligerancias. Oponerse a la política dominante es ya una parte de la política. Es perdedora o es de oposición, pero sin duda es una posición política: es el ejercicio de un cierto poder 
dentro de la sociedad. Solo por medio de algún tipo de poder se puede hacer política.

Hacer política no es solo participar en las cosas del Estado, por ejemplo, en las instituciones denominadas políticas — partidos, cámara, cargos de elección popular-, los cuales implican una abierta búsqueda del poder ${ }^{5}$. Sin duda, luchar por el poder es una parte importante de la política: se orienta al establecimiento de una dominación. Pero también es una acción política, por ejemplo, el cumplimiento de la ley; y la conservación o no del entorno. Quien evita contaminar el aire está aplicando una política y ejerciendo un poder, sin que ello implique luchar por el gobierno del Estado o la administración de sus instituciones. Sí, en cambio, está realizando una acción política, está ejerciendo un poder en la polis, dentro de la suma de todas las potencias de la comunidad.

La política es el ejercicio de un poder dentro de la comunidad. Eso puede ser desde una cosa aparentemente trivial hasta lo más elevado en la organización social. En la política, pues, hay dos estratos. Uno que quizás conviene señalarla en singular: "la política", que consistiría en el orden institucional y de gobierno. La política sería el ejercicio del poder desde los aparatos del Estado. Y en tal caso los partidos, los políticos, los gobernantes, los administradores, los funcionarios, todos ellos serían los protagonistas, tal como se entiende en los noticieros. El otro estrato es el que se significa con el término usado en plural: "las políticas", que se referirían a todo aquello que desborda directamente la lucha por el control del Estado. Entonces, un personaje de "la política", por el ejercicio de su poder a favor o en contra de algo, está ejerciendo "las políticas". 
Las instituciones educativas, las iglesias, las empresas de información y demás aparatos ideológicos son las entidades en las que las políticas encuentran concreción, pues las políticas son parte de la política.

Es difícil separarlas, porque el Estado, en tanto es la suma de todos los poderes, implica que todas las políticas son parte del Estado, incluyendo las que el individuo ejerce en su fuero privado. Aunque no hay una total diferencia técnica, sí se puede afirmar que hay una especie de diferencia semántica, entre la política, en singular, y las políticas, en plural. Entre el Estado y lo político hay una proporción análoga a la que se establece entre la generalidad estructural y el ejercicio particular. De allí que la política sea el ejercicio particular del poder, o sea, la aplicación de las políticas.

Una vez establecida la relación entre el Estado, como suma de todos los poderes de la sociedad; y la política, como el ejercicio del poder y sus tensiones entre los grupos dominantes, beligerantes y emergentes, los cuales aplican las respectivas políticas; se pasa al tercer elemento que interesa en este trabajo: la cultura.

La cultura, en principio, puede conceptuarse como un aparato ideológico, en el cual compiten por la predominancia distintas fuerzas sociales, en particular, tres frentes: religión, educación y arte. La educación y la religión parecieran estar más incluidas en el poder, puesto que se tienen claras evidencias de que se trata de instituciones; pero la institución arte oculta su evidencia en la propia renovación constante. La educación y la religión cumplen con el cometido de preservar y transmitir a las nuevas generaciones los productos, saberes y cosmovisiones (heredados del pasado) que se consideran de valor.

En el arte, al contrario, la preservación de lo valioso previo, parece serle algo exterior, ordenado en instituciones como los museos o las academias, 
que son, en cierto sentido, ajenas al proceso generador de arte. Sin embargo, la institución arte no está más lejana del poder de lo que están la educación o la religión. En tanto inserción en la cultura, cualquier posición social del artista es ya una política cultural, aun cuando no sea claro su estatus institucionalizado. El arte no está lejos de las instituciones: en las cavernas de Altamira hay pinturas y, también, el ejercicio de un poder.

La cultura puede entenderse en dos orientaciones. En principio, cultura es toda la actividad humana en lo que tiene de perdurable, de continuidad histórica: es el suceder de lo humano en el mundo, todo lo que sucede en el mundo de lo humano como orden activo o simbólico que alcanza una perduración. Dicho de otro modo, no es solo un acto, sino que es un acto con tendencia de continuidad en la comunidad. La continuidad, en este sentido, es imprescindible. Un acto en el mundo que no se impulse en esa tendencia hacia la continuidad es algo existente y, sin duda, sucede en el entorno de la cultura, pero el rango dentro del patrimonio cultural será nulo.

El estatuto de los actos no perdurables conduce a la segunda acepción, ya no tan general, en la que cultura no es todo lo que se hace en una comunidad en el sentido histórico, sino solo aquellas formas que identifican a una comunidad, lo propio de la cultura china, de la cultura azteca, lo propio de la cultura de una persona - aunque eso ya es como una reducción de la comunidad - o grupo. En este carácter, la cultura no es todo producto o proceso humano que perdura en una comunidad, sino solo aquello que confiere identidad a una comunidad en determinados aspectos, por ejemplo, la cultura musical de México en el siglo veinte. En esta segunda acepción, cultura es el conjunto de actos y símbolos de identidad en las comunidades. La política cultural estribaría en apoderarse de las perduraciones simbólicas mediante el impulso de actos y procesos identitarios y la negación de los opuestos. 
En ese entorno aparece el arte entendido como una parte de la cultura. Si ese arte identifica a una comunidad, entonces es cultura. No es viable la pregunta de si puede haber arte que no identifique, que no pertenezca a la cultura, incluso cuando el artista hace algo contrario a su comunidad -a su comunidad cultural — con el propósito de alterar sus identidades, que ahora ya incluyen la ruptura instaurada por el artista: ahora la comunidad posee una nueva identidad, que incorpora sus propias rupturas artísticas.

Las comunidades, asumidas como grupo-sujeto, de acuerdo con Lucien Goldman, no son los conjuntos de personas que habitan el mismo lugar, sino el conjunto de personas que comparten las mismas condiciones superestructurales de valores, creencias, ideas, formas simbólicas, etc. En ese caso, el sujeto del proceso del arte no sería la comunidad en la que el artista reside, sino el grupo social con el que se identifica su producción simbólica.

Sin apartarse del concepto genérico de que la cultura es el conjunto de actos y símbolos que identifican a las comunidades, se podría decir que un grupo-sujeto del arte no se define como aquellos que comparten tradiciones locales, territorio físico y expectativas valorales, sino más bien como los que comparten tradiciones, territorio y expectativas en el orden simbólico más que en el histórico-geográfico. En este aspecto particular, la comunidad no se cifra en su localización, sino en sus actos simbólicos. Por ejemplo, los escritores latinoamericanos del siglo XX tienden a identificarse con comunidades culturales europeas o estadounidenses, más que con los habitantes de los territorios latinoamericanos ${ }^{6}$. Esto es todavía más notorio en las comunidades virtuales, las cuales mediante redes informáticas comparten actos y símbolos, aunque no necesariamente compartan tradiciones o territorio. 
Resumiendo, la cultura, en general, es todo acto humano orientado a la significación histórica; en lo particular, cultura es lo que identifica a una comunidad, mediante actos y símbolos en un territorio común. Todavía más específicamente, actos y símbolos que forman una comunidad que se identifica mediante estos sin compartir territorio, o bien, por compartir un territorio virtual. En su especificidad más contemporánea, la cultura tiene más de política, de electividad: lo que en la tradición identifica a una comunidad, vira hacia lo que aquella comunidad asume para sus identidades.

Se está, entonces, ante una especie de autoconciencia de los grupos sociales, de tal modo que, en cada momento y según las diferentes opciones disponibles, se pertenece a diversas comunidades. Una artista que es estudiante y juega básquetbol, tendría tres comunidades a las cuales pertenecer. Sus preferencias tienen como trasfondo las tendencias tradicionales de más peso; pero en la inmediatez, se tienen opciones determinadas por la política cultural, que cultiva el arte, mantiene las instituciones educativas y promueve ese deporte.

Se han establecido tres elementos: el Estado, que es el depositario de los poderes de la sociedad; la política, entendida como el ejercicio de los poderes depositados en el Estado; y la cultura, que serían esos actos y símbolos que una persona acepta y que lo identifican con una comunidad. Ante eso, la política cultural consistiría en el ejercicio del poder mediante actos y símbolos con los que se identifique el individuo. La política cultural trata de comunidades en actividad simbólica; pero, dado que el poder lo ejerce el Estado, esta actividad se somete a los acotamientos del Estado: este es el que determina los límites de lo permitido y lo prohibido. 
Por ejemplo, hace no muchos años, ya en el siglo XXI, en la ciudad de León, México, un artista expuso un cuadro que figuraba a Xipe Tótec, conocido en la religión azteca como "Nuestro Señor el Desollado". Un político de derecha, funcionario del ayuntamiento, retiró la obra y prohibió que el público la percibiera, argumentando que el arte pictórico no debe mostrar pornografía -entendida por él, se supone, como la exhibición de la piel del cuerpo humano que no debe mostrarse-. El dios desollado, desde luego, está desnudo; pero no para mostrar la piel -de la que el desollado carece-, sino la carne viva. Esa evidencia escandalizó más al político en cuestión.

En el ejemplo se identifican tres aspectos. En su sentido más inmediato y personal, el artista hizo su obra — como el dios le dio a entender-y, por lo tanto, ejerció un poder individual dentro de la sociedad: produjo esa obra y no otra. Esa capacidad ejercida de expresión, de técnica, de asumir la tradición, de recuperar la historia, la comparte en un museo institucional; por lo tanto, como una presencia autorizada por el Estado, este autoriza que el artista exponga su obra en la "catedral" de la cultura de la ciudad de León, México. Dicho en términos estéticos, el Estado "consagra" -tal es el término que usa Heidegger- esa obra, exhibida en un espacio consagrado para el arte. Después, viene el político, verdadero oficiante de lo no artístico, y aunque el Estado había aceptado que se exhibiera la obra, el funcionario declara que el Estado no puede aceptar la exhibición de esa obra -que él si vio- porque sería en perjuicio del público.

En todo este proceso se está ejerciendo la política cultural: por parte del artista, al elegir arte, asunto, técnica y salida para su obra; por parte de quien autorizó la exhibición en el museo; por parte del político que prohibió la exhibición; y por parte del público, que acepta o no acepta que el funcionario de la derecha decida qué es lo debe o no percibirse. Dentro 
del Estado, además, alguien tuvo un poder dominante para permitir la exhibición y un poder beligerante que se opuso. Todo poder del Estado, visto en su conjunto, es esquizofrénico.

Octavio Paz tuvo el buen tino de llamar al Estado "el ogro filantrópico"7; de esa manera, describe la dualidad que fluctúa entre el terror y la beneficencia. Un agente del poder permite dar a conocer la obra artística, mientras otro agente del poder lo impide. A su vez, el público que asiste o no asiste a percibir la obra artística también ejerce un poder y aplica la política cultural.

En todo esto, se pueden situar tres instancias en la política de la cultura: creación, promoción y recepción. Los tres constituyen, en su conjunto, las políticas culturales, que permiten o impiden actos y símbolos que identifican a las comunidades, las cuales son múltiples dentro de un Estado. No hay una única comunidad fija, sino comunidades dinámicas que dependen, en cada momento, de ciertas afiliaciones personales de sus componentes. La política cultural muestra tres tipos de personas ejerciéndola. En su orden general, las actividades culturales tratan de financiamiento, políticas y legislación. De las tres instancias, la parte intermedia -la promoción- es la que atañe más en directo al Estado, al cual le señala la ley ese compromiso. Incluso se consigna en las leyes ${ }^{8}$ el deber del Estado para promover la cultura, aunque no para crearla.

En la dinámica social, los poderes reales no son los que administran, sino los que deciden. El artista, al tomar decisiones, se integra al orden institucional, ya sea como dominante, beligerante o emergente, con respecto a las formas de la sensibilidad ya existentes. Puesto que el Estado no es artista y no va a crear arte, lo que hará es crear las condiciones en las 
cuales el artista pueda crear y el público pueda percibir. El Estado construye la infraestructura de la sensibilidad. En ese entendido, para un político es más importante crear un edificio nuevo que crear un grupo de artistas que active los recintos ya producidos. La política, que sucede en función del financiamiento y sus legislaciones, pareciera no alcanzar a los artistas; sin embargo, el artista realiza su obra siempre en un contexto de políticas de la sensibilidad.

La sensibilidad forma una parte crucial de las políticas culturales, pues ante su ejercicio es que el Estado aprueba o reprueba actos y objetos que la amplían o la limitan. La publicación de un libro de nuevos poemas tiende a ampliar la sensibilidad, puesto que quienes detentan el poder consideran que es algo a apoyar; en cambio, la censura de un libro de poemas -por ejemplo, la versión original de Las flores del mal, de Baudelaire- tiende a limitar la sensibilidad, pues los dueños del poder deciden impedir que esa obra llegue al público ${ }^{9}$. Para la política del Estado, la visión general de la cultura debe separarse en diferentes lugares, de modo que una política cultural será solo aquello que tiene que ver con la creación artística y sus secuelas dentro de la sociedad; se desagrega, así, la política cultural frente a la educativa, la religiosa y la política, forjándose institucionalidades distintas para cada una.

Lo anterior vale, incluso, en casos de mixturas, como la cultura política, la educación artística, etc. La sensibilidad, que se cohesiona en la religión, se aprende en la escuela y se presiona en la política, mantiene un sitio de poca visibilidad en todas esas manifestaciones, en tanto se muestra como componente abierto y central en el ámbito de la cultura. Las políticas de la sensibilidad, pues, se reparten en el conjunto de los aparatos ideológicos y los productivos, pero tienen como eje visible las políticas culturales, y en particular las artísticas. 
Por un lado, el artista ejerce una política cultural al crear su obra, para la cual busca o no busca la protección del Estado; con la cual quiere o no quiere ir hacia las nuevas tendencias de la creación; busca o no los nuevos materiales. En cada una de esas decisiones se está ejerciendo una política cultural. Aunque es fundamental y permanente, tal ejercicio parece socialmente irrelevante, porque el poder que un artista puede ejercer es muy poco. Pero si el artista se convierte, por sí mismo, en una institución, entonces tiene poder; y entonces el Estado sí interviene. En estos casos, el artista se afilia al Estado, o se le contrapone, o se postula como nueva alternativa, según sea su poder dominante, beligerante o emergente. Aquí hay que recordar que el arte puede darse entre las élites o entre las masas, con sus propias especificidades.

El Estado, puesto a ser creador de cultura, opera con pérdidas. Las televisoras culturales o las editoriales del Estado son ejemplos en nuestro medio. La labor del Estado en la cultura, como se mencionó, no es crear, sino promover; y en tal sentido, controlar. Dijo un ironista que cuando el Estado se pone a crear cultura experimenta la proverbial inopia de los artistas incomprendidos. El artista convertido en institución le es más útil al Estado que una institución completa dedicada a crear cultura. El impacto en la sensibilidad de las comunidades es más poderoso cuando lo elaboran sus artistas que cuando lo rigen sus políticos.

Octavio Paz, por ejemplo, ha influido más en la sensibilidad latinoamericana -y no solo en la latinoamericana- que todas las acciones sumadas de los consejos culturales e instituciones promotoras. Un artista convertido en institución tiene más poder que el Estado, en lo que atañe a la creación de cultura, lo cual revela el verdadero secreto de la política cultural: cada uno tiene que hacer lo suyo. Ahora bien, si el artista se 
convierte en una institución, entonces se vuelve sujeto de un presupuesto, una legislación y una política. La Fundación Octavio Paz sería el ejemplo concurrente. En un giro esperable, los artistas, en su vinculación con el Estado, a veces ponen la promoción de su obra por encima de la creación: su sensibilidad se amolda a las políticas de la sensación. Al final, puede suceder lo que alguna vez se afirmó: que los jóvenes escritores están aprendiendo a publicar antes de aprender a escribir. Y eso es aplicable a todas las áreas "protegidas" por el Estado. No obstante, las contradicciones mismas dentro de la sociedad permiten la convivencia de políticas culturales contradictorias, aunque todas ellas definidas de frente al poder.

Si bien hay una política cultural del Estado, cada institución, artista o grupo de artistas, tiene su propia posición política en la cultura: su política cultural.

Los rubros en los que se manifiesta la política de la sensación, como aplicación de la política cultural, son dos: actos y símbolos. Competen a la persona los actos de creación; y su determinación simbólica es portada por los objetos creados en el proceso. El artista define (inventa o impulsa) su propia creación de acuerdo con su técnica y capacidades; y lo representa materialmente dentro de la comunidad que compone su grupo-sujeto. De igual forma, mediante sus poderes el Estado permite o prohíbe esos actos y símbolos en acotaciones específicas, dándole una legislación, una política y una asignación pecuniaria.

Por ejemplo, en una institución de prestigio literario como la Fundación para las Letras Mexicanas, la aplicación de sus políticas culturales muestra la subyacente política de la sensibilidad. La Fundación establece sus políticas: solicitantes menores de 30 años y residir en la Ciudad de México. Asigna un presupuesto: aproximadamente mil dólares mensuales durante 
un año. Determina una normatividad: "Ya que se trata de una beca de formación y no de reconocimiento a la obra realizada, los becarios se obligan a asistir diariamente a la sede de la Fundación; adquieren el compromiso de dedicar tiempo completo al desarrollo de su proyecto, participar en la elaboración de la Enciclopedia de la Literatura en México, asistir a todas las actividades del programa que les sean indicadas". ${ }^{10}$

No se discutirá lo expresado por críticos culturales, quienes afirman que iniciativas como esa se establecen para comprar autores jóvenes, fortalecer el centralismo y aplanar las diversidades regionales. Basta con señalar la claridad ejemplar con la que se determina su política, financiamiento y legislación.

Toda la institucionalidad del Estado en este campo tiene la misión de promover actos y símbolos, los cuales refuerzan al poder dominante. Quien no se beneficia de esas ayudas institucionales puede ocuparse en actos y símbolos en contra de la dominación, quedando, aparentemente, fuera de la institucionalidad. Eso implica que la marginación provocaría una sensibilidad atípica, lejana a la del conjunto de la comunidad. En cierto sentido, todo arte nuevo solo puede ser creado fuera de la institucionalidad dominante; y solo en el contexto de la institucionalidad dominante se puede promover. Eso es lo más natural en las políticas culturales: cuando los artistas se han institucionalizado, su inventiva queda en entredicho. En el momento en que el innovador se convierte en una institución difícilmente puede evadir todo lo que se implica de política, legislación y financiamiento.

La renovación de la sensibilidad requiere que el Estado permita sectores atípicos y marginales, los cuales, si se aprecian de utilidad, son absorbidos por la institucionalidad dominante. En esa dirección, el arte nuevo y la 
nueva sensibilidad se gestan en un entorno de poder emergente, que se desplaza más allá de la pugna entre lo dominante y lo beligerante. Una vez estructurada la nueva sensibilidad en esos "laboratorios" emergentes, se perfilan las políticas que le serán propias, estableciéndose primero como beligerantes, es decir, con éxito plausible y opuestas a las formas dominantes; hasta llegar a ser la manifestación misma del espectro de la dominación.

Por el lado del público, se está ante una política cultural subsidiaria. Dado que el público viene cuando ya se creó el objeto que encarna los actos y símbolos, o sea cuando algo ya producido por el creador de cultura se promueve por parte del Estado, la aceptación llega desde rumbos insospechados. Por ejemplo, el momento histórico en que el joven Pablo Ruiz Picasso viaja a París, él crea en el entorno una sensibilidad emergente. Su obra inicial no es aceptada y tiene que arrojar a la chimenea una parte de la obra para sobrevivir en el invierno. Sin embargo, cuando el pintor se convierte en una institución y se promueve ya como Picasso, el público se divide en dos grupos: los que aprecian la obra de Picasso y los que ven la marca registrada Picasso. En la dinámica social, son dos tipos diferentes: el público del arte y el público de las políticas culturales institucionales respecto del arte. El público del arte se asocia a una sensibilidad renovante; y el público de la institución a una reiterativa.

La institucionalización de la sensibilidad conduce a un desdoblamiento metafísico de la política cultural: se forman sociedades de apoyo a la institución -amigos del museo, patronatos, fundaciones y demás órganoscomo una epifanía que revela a la política cultural como vehículo para el cumplimiento de la propia política cultural. En el primer nivel, la promoción apoya la creación; y en este segundo plano, la promoción apoya a la promoción. Patronatos y mecenazgos se orientan a promover el 
desarrollo cultural; el objetivo no es renovar la sensibilidad, sino atraer más gente a la institucionalidad. En tal caso, el público no es llevado al arte, sino a la institución. No se pretende una mejora en sus componentes de sensibilidad -percepción, sentimientos, sensibilidad- y sí que se cumplan las metas institucionales. Se cumplen las políticas de la cultura mientras las políticas de la sensación quedan preteridas, por ser numéricamente imponderables, no tratables mediante facturaciones presupuestales.

El ogro filantrópico, como señala Octavio Paz, evidencia el carácter de monstruo que sustenta al Estado; pero a la vez deja notar, a modo de filantropía, el otorgamiento de prebendas: la filantropía impulsa las condiciones para la renovación de la sensibilidad, mientras la "ogridad" las limita. Son dos aspectos de una misma política, por la cual el Estado pega y paga. El movimiento de renovación se mediatiza, en tanto surge otra renovación para ser, a su vez, asimilada. Como será claro, en términos de las políticas de la sensación, renovar las formas por medio del arte es la forma privilegiada de una futura amplitud de la dominación.

Esta política doble, ambigua, se revela en todos los estratos. A los artistas se les permite hacer lo que quieran, ya sea dentro de las dádivas institucionales o al margen de estas; al final, unos serán promovidos y otros no. Desde un punto de vista del poder, las obras promovidas muy bien pueden no gustarle a nadie; pero se promueven por estar alineadas a las políticas del Estado, no importa qué tipo de arte se hace, lo que importa es que está dentro. Desde un punto de mira del artista, una vez que el Estado lo promueve, su política personal está limitada, ya no puede crear con independencia de juicio ni de criterio, porque ya es un promovido del Estado. 
Lo irónico de estos desplantes de la sensibilidad es que no hay mejor forma de contener a un artista que premiándolo por parte del Estado. Desde el punto de vista del público -que aparece como operador de una política cultural subsidiaria-, lo que prefiere el Estado es el público institucional, que exige novedades controladas y está de acuerdo con ir llevando las cosas poco a poco. El público institucional pareciera contento con la tradición, por lo que la política cultural del Estado se orientaría sobre todo al rescate de lo folclórico y el mantenimiento de lo popular; y solo en mínima parte a las nuevas creaciones. Las instituciones dedican la mayor parte de sus presupuestos y orientan sus normas a la reiteración de las formas de la sensibilidad ya asimiladas.

Ante esa expectativa de la popularización cultural percibida como popularidad política, las instituciones -incluso las más nobles, como lo son las universidades- se someten a la promoción del arte popular en sus formas más comerciales, resultando subsidiarias de las cadenas televisoras y radiodifusoras, que son los medios óptimos de lo popular. Por un lado, el público siempre es subsidiario, puesto que depende de que el objeto cultural ya esté producido; por otro lado, el artista está siempre en peligro de ser subsidiario de la institucionalidad. En cualquier caso, conviene notar cómo desde el poder se determina la inmensa mayoría de lo que la gente está autorizada a sentir.

De frente a la autorización del Estado, la política cultural se finca en una política de la sensación: desde el Estado se controlan sentidos. Al vincularse a un objeto de la cultura, los sentidos son controlados por el Estado. Y quizás no solo en los sentidos, sino en la imaginación misma, en tanto sus contenidos están derivados de los sentidos. 
Siguiendo a Kant, el humano imagina cosas a partir de lo que se presenta a los sentidos. El público, ya de suyo subsidiario de las políticas culturales del Estado, se convierte en un repetidor de lo más simple de los objetos de los sentidos, de lo más controlado, de lo más censurado: no hay nada en la cultura popular que sea opuesto al poder dominante del Estado. Al contrario, es la reiteración de la integración del público a una política de control; y eso es avasallador. Octavio Paz, muy optimista, dijo que las televisoras de contenidos de alta cultura rondaban el $2 \%$ del público; pero incluso ese mínimo sector de las cosas que se pueden percibir en la alta cultura no está al margen de los controles del Estado. Es muy difícil percibir algo que venga en directo de la invención emergente, no de la institucionalidad, porque para que el objeto cultural llegue debe pasa por la institucionalidad que la promueve. Incluso se promueve como "opuesto" al control del Estado. La dificultad de percibir lo nuevo hace visible la eficacia del poder del Estado sobre los sentidos de los habitantes.

Sin embargo, las políticas institucionales se concretan por la acción de las personas. Como se dijo anteriormente, un funcionario va a decir que no y otro dirá que sí; uno permitirá la ampliación de la sensibilidad y otro la impedirá. El hecho de que existan contradicciones en las políticas del Estado, permite resquicios en los que se puede vislumbrar el orden originario de la creación o definitivamente insertarse en la cultura de masas. El poder busca darle forma a la sensibilidad y construir como iguales a todos dentro de la comunidad. El poder de resistencia o de invención, trata generar personas originales, diferentes de los demás miembros de la comunidad.

En ambos extremos, se trata de convertirnos en otros: en los que seremos, distintos a los que somos. Y debemos aceptarlo, porque esa fluctuación 
entre lo sabido y lo desconocido es el orden mismo de la sensibilidad. Cuando percibimos algo, nos lo apropiamos; y al apropiarlo dejamos de ser los que éramos. Hay una transformación en nosotros por medio de la percepción; y estas percepciones están en función del poder. Hay que deliberar y decidir con qué sensaciones queremos formarnos. El cuerpo se compone de lo que se ingiere y la sensibilidad de lo que se percibe.

Las políticas de la sensación resultan, en última instancia, criterios para la construcción de lo humano y de lo social en el interior de cada individuo. El poder cohesiona mediante el control de las sensaciones disponibles, permitiendo unas y prohibiendo otras. El arte inventa sensaciones antes desconocidas, por lo cual es de urgencia para el poder establecer los ámbitos y límites donde la renovación de la sensibilidad social podrá experimentarse sin destruir la nación, la sociedad o el universo. Cada uno tiene ante sí la ubicación posible para el futuro de sus sensaciones, aunque deba enfrentarse con la filantropía generosa del ogro o con el rostro terrible y la fuerza monstruosa de su filantropía.

Aunque a principios de 1830 las compañías líricas dejaron Buenos Aires, ${ }^{3}$ la música siguió generando producciones en torno a sus principales actividades y géneros musicales. ${ }^{4}$ En este marco, el presente trabajo busca indagar sobre la función social y estética atribuida a la música en el diario Boletín Musical (1837) y en La Moda (1837-38), soportes vinculados al accionar de la denominada Generación del '37. Dicho objetivo pretende, a su vez, mostrar cómo en el discurso de la prensa predominaron ciertos tópicos románticos que erigieron a lo musical como una práctica social y artística fundamental en la constitución de un nuevo orden político. ${ }^{5}$

En este sentido, los diarios describieron la capacidad musical como una posesión natural e inherente a todos los sujetos y no como la consecuencia 
de un proceso de aprendizaje racional y exclusivo de la elite, tal como había sido entendida durante la década de 1820. La hipótesis que guía este trabajo está orientada a pensar que, valiéndose del romanticismo como paradigma de pensamiento, los diarios erigieron a la música como una práctica inclusiva, al alcance de la totalidad del pueblo, el cual se consideraba destinatario de un programa civilizador impulsado por la "nueva generación romántica". Al discutir muchos de los supuestos de la ilustración, en tanto una tradición que consideraron obsoleta, lo que realmente estaban haciendo era cuestionar los limitados alcances de las políticas culturales del gobierno precedente y, derivado de ello, afirmar su apoyo al gobernador actual, Juan Manuel de Rosas.

Para concretar dichos objetivos, se organizó el trabajo en cuatro apartados. En un primer momento se busca indagar en torno a la circulación de revistas y soportes literarios, así como en espacios y trayectorias personales que, desde inicios de la década de 1830, habilitaron la existencia de ambos diarios. Asimismo, se comentan brevemente las particularidades de la edición y tirada del Boletín Musical y La Moda. Posteriormente, en un segundo apartado, se busca mostrar la predominancia de dos conceptos románticos que normaron la referencia a la música y a los músicos europeos: pueblo y genio. En un tercer momento, se analizan las referencias a los músicos locales y a la música como un atributo que, lejos de ser entendido como una práctica racional, fue pensado como natural e inconsciente. Por último, se indaga sobre los lineamientos y propuestas defendidas por ambos diarios, a fin de generar un arte local y, derivado de ello, constituir un nuevo orden musical, necesario para inaugurar un nuevo momento político. 
Althusser, L. (1977). Posiciones. Barcelona: Anagrama.

\section{Referencias}

Bierce, A. (1993). Devil's Dictionary. Reprint of the Neale Publishing Company 1911 edition. New York: Dover.

Duque, A. (1984). El suicidio de la modernidad. Madrid: Bruguera.

Duverger, M. (1951). Les partis politiques. París: Armand Colin.

Goldmann, L. (1966). Sciences humaines et philosophie. Suivi de structuralisme génétique et création littéraire. París: Gonthier.

Paz, O. (1979). El ogro filantrópico. México: Joaquín Mortiz.

Valdivia, B. (1997). "Notas para una tipología de la censura". En: Tiempo, 61, pp. 22-24.

Valdivia, B. (2011). Filosofia del suicida y otros ensayos sobre sensación y libertad. Berlín: EAE. 
1. Véase mi libro Filosofia del suicida y otros ensayos sobre sensación y libertad. EAE, Berlín, 2011, pp. 126-127.

2. Es relevante la observación de Aquilino Duque respecto del paso de la sociedad prohibitiva a la permisiva. Véase El suicidio de la modernidad, Bruguera, Madrid, 1984.

3. Como bien lo analizó Louis Althusser en "Ideología y aparatos ideológicos del Estado”. Posiciones. Anagrama, Barcelona, 1977.

4. En su Devil's Dictionary, Ambrose Bierce dice que elector es "quien goza del sagrado privilegio de votar por el candidato que otros eligieron" (One who enjoys the sacred privilege of voting for the man of another man's choice).

5. Maurice Duverger, en su clásico Les partis politiques (Armand Colin, París, 1951), dice que los partidos en forma expresa buscan conquistar el poder político y ejercerlo.

6. El reconocimiento, la producción, y hasta la nacionalidad, se trasladan al orbe simbólico europeo. Las vanguardias o el boom serían ejemplos claros. Más recientes son los casos de Mario Benedetti y Mario Vargas Llosa, que se nacionalizan como ciudadanos del Reino de España, desplazando su origen latinoamericano. O la residencia permanente en países europeos, como lo eligió Carlos Fuentes.

7. Octavio Paz. El ogro filantrópico. Joaquín Mortiz, México, 1979. 
8. Por ejemplo, en la Constitución colombiana de 1991: “Artículo 70. El Estado tiene el deber de promover y fomentar el acceso a la cultura". O la mexicana, en su Artículo 4: "El Estado promoverá los medios para la difusión y desarrollo de la cultura, atendiendo a la diversidad cultural en todas sus manifestaciones y expresiones con pleno respeto a la libertad creativa".

9. Que la censura es algo que limita al público y no al artista es algo que abordo con más detalle en mi ensayo "Notas para una tipología de la censura", pp. 22-24 de: Tiempo \# 61, México, 1997.

10. En el sitio www.flm.mx puede verse la convocatoria completa.

Recibido: 03-enero-2016 Aceptado: 10-abril-2016

Todos los derechos reservados. Universidad de Costa Rica. Esta revista se encuentra licenciada con Creative Commons Reconocimiento-NoComercialSinObraDerivada 3.0 Costa Rica. (CC BY-NC-SA 3.0 CR)

Correo electrónico: humanidades@ucr.ac.cr Sitio web: http://revistas.ucr.ac.cr/index.php/humanidades 